\title{
Toward more reliable repair of ruptured sinus of Valsalva
}

\author{
Masashi Komeda, MD, PhD, Osaka, Japan
}

\footnotetext{
From the Department of Cardiovascular Surgery, Jinsenkai Hospital, Osaka, Japan.

Disclosures: Author has nothing to disclose with regard to commercial support.

Read at The American Association for Thoracic Surgery Aortic Symposium Workshop 2015, Kobe, Japan, October 16, 2015.

Received for publication May 26, 2016; revisions received July 1, 2016; accepted for publication July 8, 2016; available ahead of print Aug 30, 2016

Address for reprints: Masashi Komeda, MD, PhD, Department of Cardiovascular Surgery, Jinsenkai Hospital, 8-

2-22, Morofuku, Daito, Osaka 574-0044, Japan (E-mail: zeek-m@bf7.so-net.ne.jp).

J Thorac Cardiovasc Surg 2016;152:1442-4

$0022-5223 / \$ 36.00$

Copyright $(c) 2016$ by The American Association for Thoracic Surgery

http://dx.doi.org/10.1016/j.jtcvs.2016.07.053
}

Video clip is available online.

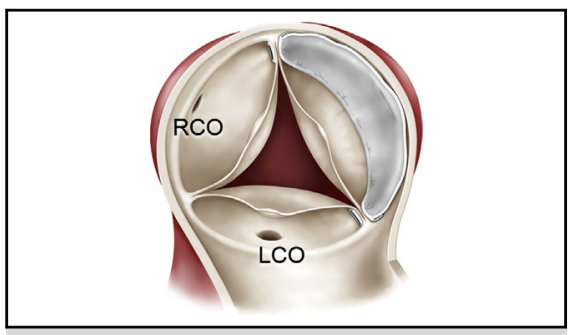

Stable repair of SV.

\section{Central Message}

This report describes a novel surgical method to repair the ruptured SV aneurysm. The method uses only strong fibrous skeleton tissue to stabilize the suture line of the patch.

See Editorial Commentary page 1444
In surgery for a ruptured sinus of Valsalva (SV) aneurysm, the ruptured site is traditionally closed directly or by using a patch. ${ }^{1}$ However, the tissue of and around the ruptured site is thin and fragile, ${ }^{2}$ which may cause residual or recurred shunt. To my knowledge, no surgical procedure has been reported that stabilizes the repair site for a ruptured SV aneurysm. This report describes a novel repair method.

\section{Case Reports}

The first patient was a 25-year-old man who underwent direct closure of a ruptured SV aneurysm at another hospital. In 6 months, heart failure developed in the patient as the result of rupture of the closure site (Figure 1), and he presented to Jinsenkai Hospital. A reoperation was performed. The lower-middle part of the noncoronary SV near the direct closure site was torn, with the previous pledgets remaining. A patch was placed by suturing fibrous, strong tissue, such as an aortic ring (Figure 2, A). A bovine pericardial patch was sewn to exclude the whole noncoronary SV (Figure 2, B). The size and shape of the patch were designed to restore the normal noncoronary ring and SV to prevent aortic insufficiency in the future. The top part of the suture line was later incorporated into the aortotomy line, which was reinforced by a Teflon felt strip. The patient's postoperative course was uneventful, and he is in New York Heart Association (NHYA) class I with no shunt and a normal SV (Figure 1) 4.5 years after the redo surgery.

The second patient was a 33-year-old woman in whom recurrent shunt of the noncoronary SV developed 2 months after the initial operation at a nearby hospital where she underwent patch closure for a ruptured SV aneurysm.
Echocardiography showed a large amount of left-right shunt and a dilated right heart. Reoperation was performed in a similar fashion to that of the first patient by using the
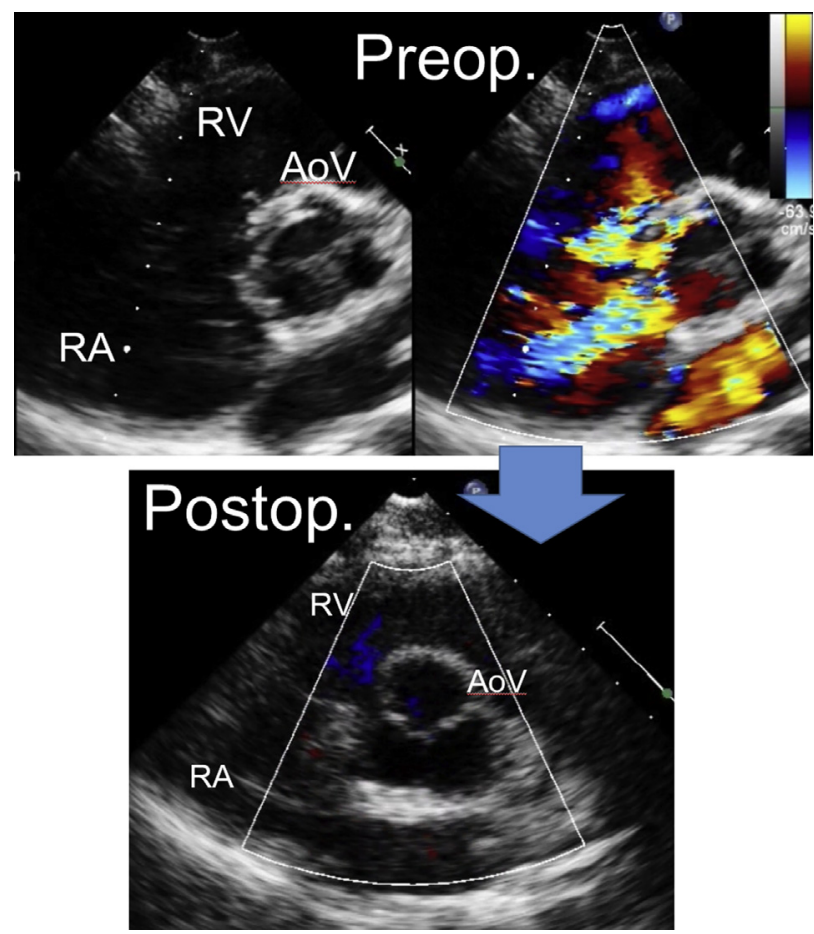

FIGURE 1. Echocardiography before and after surgery in the first patient. Top: 2 massive shunts at the ruptured SV with right heart dilatation preoperatively. Bottom: no shunt or right heart dilatation postoperatively. $R V$, Right ventricle; $A o V$, aortic valve; $R A$, right atrium. 


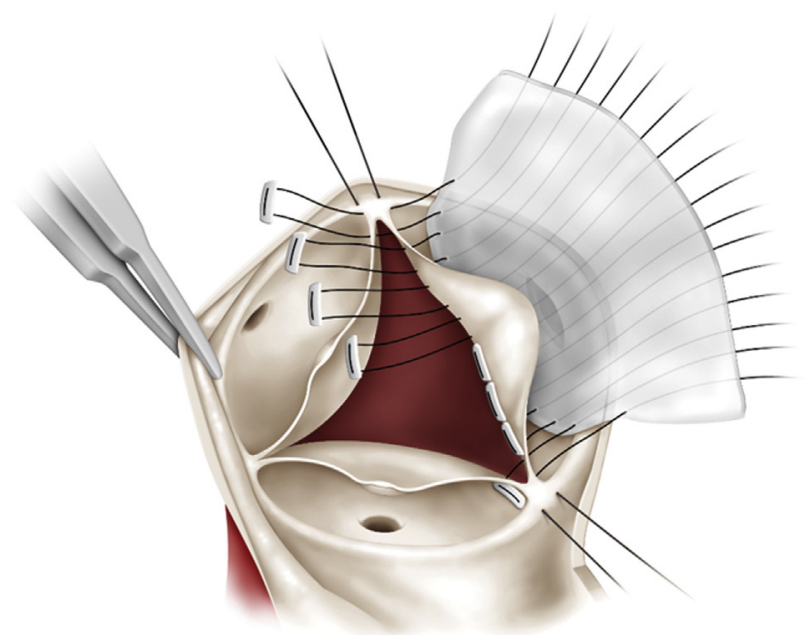

A

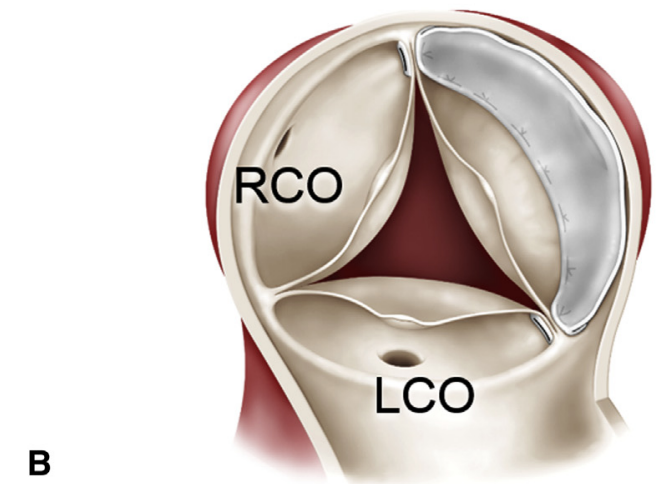

FIGURE 2. Operative procedures. A, 2-0 polypropylene buttress sutures were passed through the aortic ring from the left ventricular side to the Valsalva side, and other sutures above the commissure level were placed on the healthy aortic wall. Note that the sutures at commissure were placed from the adjacent SV. B, Bovine pericardial patch was sewn and placed on the Valsalva to exclude the whole noncoronary SV including the rupture site. Note that all knots are located in the space between the patch and the $\mathrm{SV}$. RCO, Right coronary orifice; $L C O$, left coronary orifice.

bovine pericardium. There were 2 holes $(3 \times 5 \mathrm{~mm}$ and $1 \times 2 \mathrm{~mm}$ ) in the lower-middle part of the redundant noncoronary SV with no previous patch. After suturing the new patch, a few small pledgets were left in the space between the patch and the SV wall to facilitate early thrombi formation. The patient has a normal SV with no shunt and is in NYHA class I activity 3 years after the redo surgery.

The third patient was a 60-year-old man who had heart failure with leakage in the noncoronary SV aneurysm (Video 1). Echocardiography showed a massive left-right shunt and pulmonary hypertension. The operation was performed in the same fashion as in the first 2 patients by using the bovine patch. The rupture site $(4 \times 5 \mathrm{~mm})$ was located in the middle-lower noncoronary SV a little closer to the right-coronary SV. The patient is in NYHA class I with a normal SV and no shunt 2 years after the surgery.

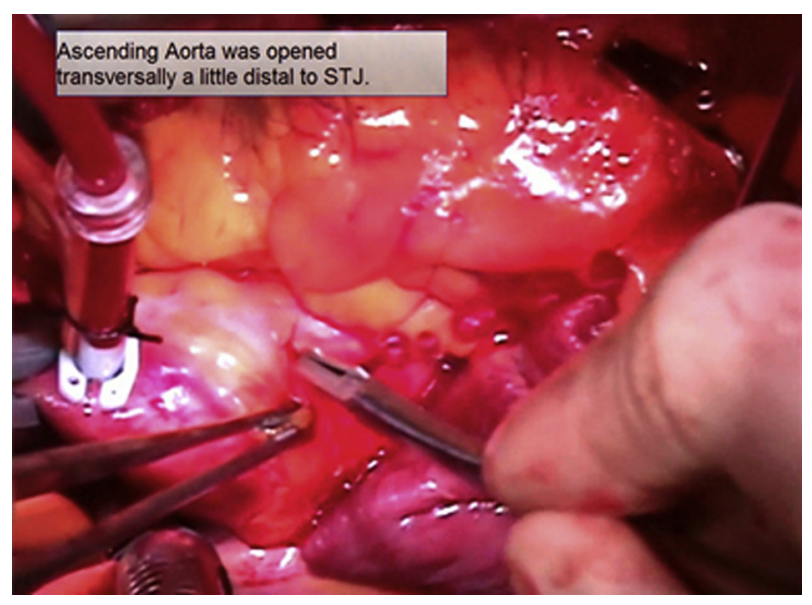

VIDEO 1. Ascending aorta was opened transversally a bit distal to the sinotubular junction. STJ, Sinotubular junction. Video available at: http:// www.jtcvsonline.org/article/S0022-5223(16)30873-X/addons.

\section{DISCUSSION}

These 3 case reports have described direct or patch closure $^{1}$ in surgery for a ruptured SV. However, early recurrent shunt flow often was observed because the suture line was fragile. In fact, histopathology of the SV in patients with a ruptured SV showed a lack of normal elastic tissue media of the aorta. ${ }^{2}$ Furthermore, the foregoing methods might lead to aortic valve insufficiency in the future because of a change in the SV geometry.

We developed a surgical repair using just strong and reliable tissue around the ruptured SV aneurysm. We now believe that a suture line for the patch should not be on the wall of the SV, whether in primary or redo case. We previously reported an "exclusion" technique for a postinfarction ventricular septum defect in which we placed stitches just on reliable tissue, staying away from the infarction. ${ }^{4}$ In the current report, we applied a similar concept to the ruptured SV aneurysm.

Another potential merit of the "exclusion" method is that it can protect the aortic ring from deformity and aortic insufficiency, because the patch does not change in size or shape for a long time. Technically, our method echoes in part Sarsam and Yacoub's ${ }^{5}$ remodeling surgery for the aortic root. Thus, experience with the root surgery may make our method more comfortable to use.

\section{CONCLUSIONS}

Although our experience comprises only 3 patients and the follow-up is 2 to 4.5 years, the technique seems sound from anatomic and clinical viewpoints, and it may improve the surgical results for a ruptured SV aneurysm. Further investigation is warranted. 
The author thanks Masanobu Maeda, MD, Department of Cardiac Surgery, Aichi Children's Health and Medical Center, for valuable advice.

\section{References}

1. Azakie A, David TE, Peniston CM. Ruptured sinus of Valsalva aneurysm: early recurrence and fate of the aortic valve. Ann Thorac Surg. 2000;70:1466-71.
2. Van Son JAM, Sim EKW, Starr A. Morphometric features of ruptured congenital sinus of Valsalva aneurysm implication for surgical treatment. J Cardiovasc Surg. 1995;36:433-6

3. Takach TJ, Reul GJ, Duncan JM. Sinus of Valsalva aneurysm or fistula: management and outcome. Ann Thorac Surg. 1999;68:1573-7.

4. Komeda M, Fremes SE, David TE. Surgical repair of postinfarction ventricular septal defect. Circulation. 1990;82(Suppl):IV243-7.

5. Sarsam MA, Yacoub M. Remodeling of the aortic valve annulus. J Thorac Cardiovasc Surg. 1993;105:435-8.

\title{
EDITORIAL COMMENTARY
}

\section{Sinus of Valsalva aneurysms: Stabilizing the repair destabilizing the aortic valve?}

\author{
M. Sertaç Çiçek, MD, FACC
}

\author{
From the Anadolu Medical Center, Section of Cardiovascular Surgery, Istanbul, Turkey. \\ Disclosures: Author has nothing to disclose with regard to commercial support. \\ Received for publication Aug 1, 2016; accepted for publication Aug 1, 2016; available ahead of print Sept 3, 2016. \\ Address for reprints: M. Sertaç Çiçek, MD, FACC, Anadolu Medical Center, Section of Cardiovascular Surgery, \\ Cumhuriyet Mahallesi, 2255 Sokak No:3, Bayramoglu 41400, Istanbul, Turkey (E-mail: scicek@mac.com). \\ J Thorac Cardiovasc Surg 2016;152:1444-5 \\ $0022-5223 / \$ 36.00$ \\ Copyright (c) 2016 by The American Association for Thoracic Surgery \\ http://dx.doi.org/10.1016/j.jtcvs.2016.08.001
}

Sinus of Valsalva aneurysm (SVA) is a rare cardiac malformation, frequently originating from the right coronary sinus and less frequently from the noncoronary and left coronary sinuses. Since the first successful repair reported by Lillehei and colleagues in 1957, ${ }^{1}$ different surgical techniques including primary closure, patch closure, and different approaches (transaortic, transatrial/ventricular, or combined) have been used with low risk and excellent early and long-term outcomes. ${ }^{2}$ The goals of the repair are to exclude abnormal tissue, to close the aneurysm securely, and to repair any associated defect without distorting the aortic valve cusps or causing heart block. Aortic valve abnormalities and regurgitation are common, with a reported incidence of aortic regurgitation (AR) as high as $41 \%{ }^{3}$ Recurrent or de novo AR is a critical problem following the surgical repair, although the risk of a recurrent fistula or ventricular septal defect is minimal in the current era. It has been reported that primary suture closure has the potential disadvantages of recurrent rupture due to increased suture line stress, and of deforming the aortic valve complex with eventual aortic incompetence. ${ }^{3}$ However, Jung and colleagues ${ }^{4}$ reported more recently that transaortic repair may cause postoperative AR by progressive distortion of the aortic sinus geometry. Autopsy studies have shown that

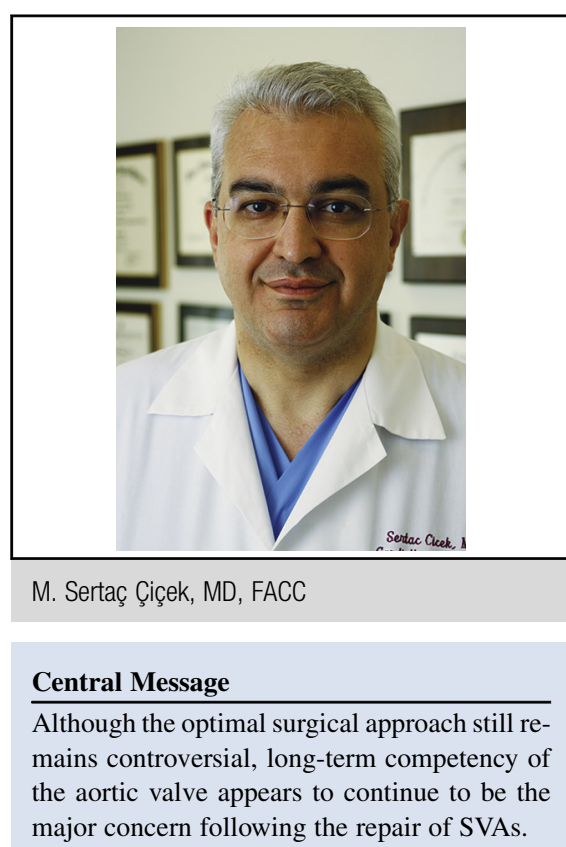

See Article page 1442

the deficiency of elastic tissue between the annulus and aortic media extends an average of 4 to $5 \mathrm{~mm}$ beyond the apparent rupture hole. ${ }^{5}$ This anatomic substrate raises issues about the optimal technique for closure of the defect, which theoretically should exclude the aneurysmatic tissue.

In this issue of the Journal of Thoracic and Cardiovascular Surgery, Dr Komeda reports a modification of transaortic patch repair, excluding the aneurysmal tissue and stabilizing the annulus in 3 patients with satisfactory early 